\title{
Input-Output Feedback Linearization Control of a Cascaded H-Bridge Multilevel Inverter
}

\author{
Abir Rehaoulia, Mahmoud Hamouda, and Farhat Fnaiech \\ Equipe SICISI, Ecole Supérieure des Sciences et Techniques de Tunis, University of Tunis, Tunisia \\ abir_reh@yahoo.fr_mamahmoud.hamouda@isetso.rnu.tn fnaiech@ieee.org
}

\begin{abstract}
This paper proposes a voltage controller for Cascaded H-bridge three-phase multilevel inverters operating in islanded mode with constant-amplitude constant-frequency output voltages. For this purpose, a non linear state-space model of the converter feeding a three-phase load via a second order LC filter is developed. Next, an input-output feedback linearization controller is designed so as to drive the output voltages to track the target references.

Numerical simulations carried out on a 7 level inverter emphasize the effectiveness of the proposed model and control law. Based on feedback linearization strategy, the closed loop response of the system is stable even in case of disturbances. The transient state is extremely short and presents small overshoots.
\end{abstract}

Keywords- Multilevel inverter; H-Bridge; PWM; feedback linearization

\section{INTRODUCTION}

Due to their plentiful benefits over conventional two-level inverters, multilevel topologies have been considered as an interesting research topic to focus on. Multilevel inverters feature reduced voltage stress on switches [1], low harmonic distortions of output waveforms as well as less output voltage swing $\frac{\mathbf{d v}}{\mathbf{d t}}[2,3]$. Accordingly, they are widely recommended either for medium or high power /voltage applications.

Besides, various topologies have been reported in literature. But three major types are still the most relevant: Neutral Point Clamped Diodes (NPC), Flying Capacitors (FC) and Cascaded $\mathrm{H}$-Bridges (CHB). Among them, the H-bridge inverter is less cumbersome since it requires the least number of components to achieve the same number of levels and doesn't need extra clamping diodes and capacitors. Hence, the problem related to voltage capacitors balancing does not arise minimizing the complexity of the control strategy. Unlike NPC and FC, the switches of H-Bridge inverter withstand the same voltage stress on off state. Furthermore, the modular layout of each converter arm ensures a good efficiency as it simplifies maintenance by replacing only the faulty bridge. It also seems to be a promising alternative for future energy because it enables the connection with renewable energy sources like photovoltaic and fuel cells [4].
In this paper, we are interested in CHB multilevel inverters operating with constant amplitude constant frequency output voltages. For this purpose, a state-space model as well as a non linear control law based on exact feedback linearization were developed to achieve the target objective independently of load variations. This method has the aim to handle nonlinearities in the system and turn them straightforwardly to linear ones via input-output relationships [3, 5-9].

The present paper is organized as follows. Section II describes the general state-space model of multilevel H-Bridge converter's supplying a resistive load. The proposed model is next extended to arbitrary load case. Section III, describes in detail the design procedure of the proposed non linear controller based on exact input-output linearization theory. In section IV, numerical simulations are carried out to highlight the performances of the proposed control strategy and prove its robustness. Finally, some concluding remarks are given in section $\mathrm{V}$.

\section{CONVERTER's MODELING}

Fig. 1 below depicts a general power circuit of a cascaded $\mathrm{H}$ bridge multilevel three-phase inverter. As the main objective of this paper is to control the output filter voltages so as they follow a target frequency and voltage references, a state-space model of the converter will be developed to express the dynamics of these voltages in terms of the converter's switching functions as well as the remaining DC and AC signals. In this section two different models will be developed. The first one considers the converter feeding the output filter and resistive loads whereas the second model will be more generalized by assuming that the load is not known.

\section{A. Converter's modeling with known resistive load}

In this section the whole system under study including the converter, the output filter, and the load is depicted in Fig.1. The modulated output voltages $U_{A}, U_{B}$, and $U_{C}$ can subsequently be expressed in terms of the dc voltages as follows: 


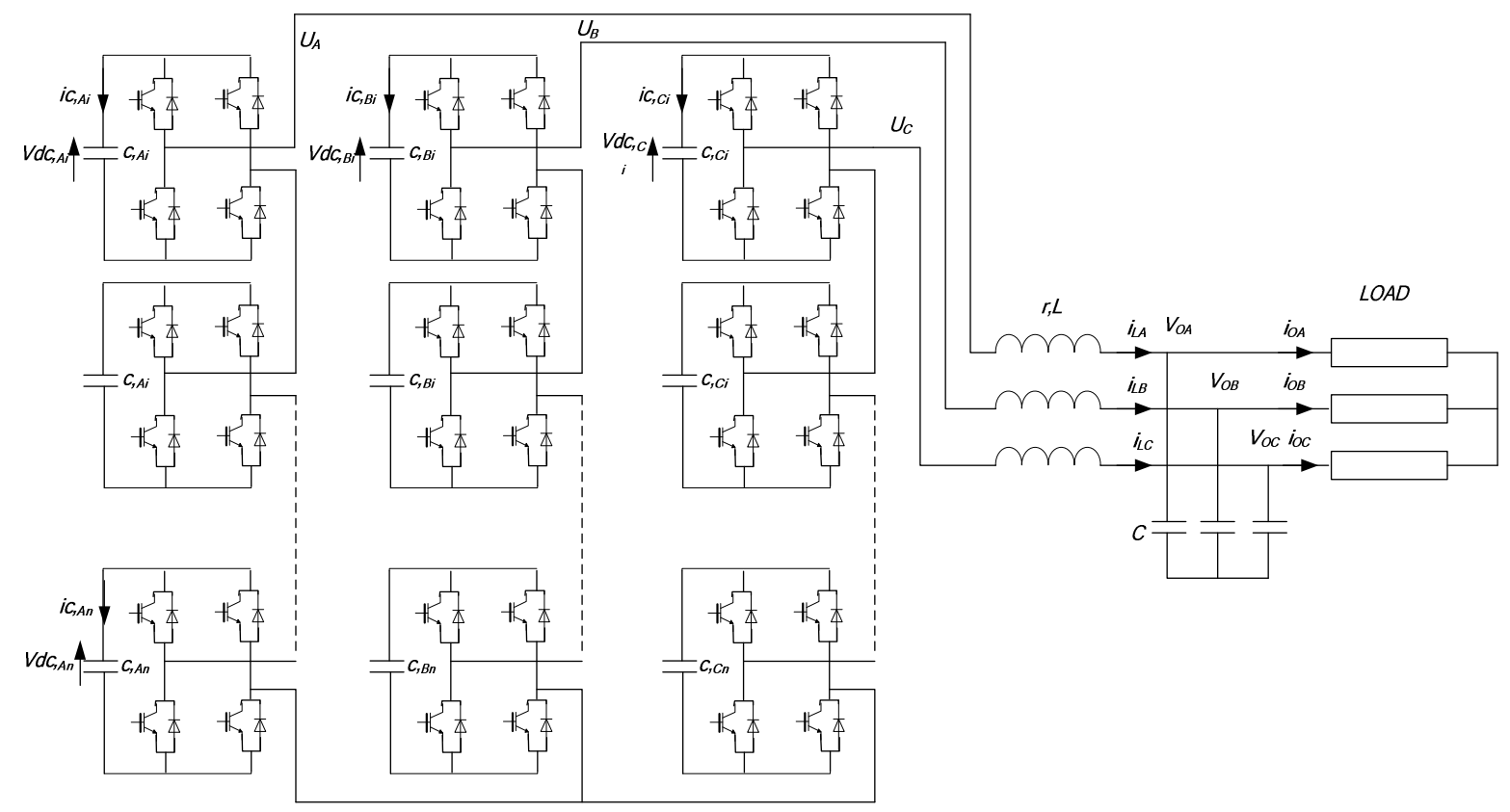

Figure1. Topology of an H-bridge arm composed by n cells in series.

$$
\left\{\begin{array}{l}
U_{A}=\sum_{i=1}^{n} S_{A i} V_{d c, A i} \\
U_{B}=\sum_{i=1}^{n} S_{B i} V_{d c, B i} \\
U_{C}=\sum_{i=1}^{n} S_{C i} V_{d c, C i}
\end{array}\right.
$$

In (1), $n$ denotes the number of dc source for each inverter's leg. $S_{x i}(x=A, B, C)$ and $(i=1,2, \ldots n)$ denotes a switching function which depends on the switching state of the H-bridge inverter connected to the dc voltage named $\mathrm{V}_{\mathrm{dc}, \mathrm{xi}}$.

Accordingly, the state space model of the converter can be expressed in a stationary three phase frame as:

$$
\left\{\begin{array}{l}
\frac{d}{d t} V_{O A}=-\frac{1}{R C} V_{O A}+\frac{1}{C} i_{L A} \\
\frac{d}{d t} V_{O B}=-\frac{1}{R C} V_{O B}+\frac{1}{C} i_{L B} \\
\frac{d}{d t} V_{O C}=-\frac{1}{R C} V_{O C}+\frac{1}{C} i_{L C} \\
\frac{d}{d t} i_{L A}=-\frac{r}{L} i_{L A}-\frac{1}{L} V_{O A}+\frac{1}{L} \sum_{i=1}^{n} S_{A i} V_{d c, A i} \\
\frac{d}{d t} i_{L B}=-\frac{r}{L} i_{L B}-\frac{1}{L} V_{O B}+\frac{1}{L} \sum_{i=1}^{n} S_{B i} V_{d c, B i} \\
\frac{d}{d t} i_{L C}=-\frac{r}{L} i_{L C}-\frac{1}{L} V_{O C}+\frac{1}{L} \sum_{i=1}^{n} S_{C i} V_{d c, C i} \\
\frac{d}{d t} V_{d c, x i}=\frac{1}{c_{x i}} i_{c x i}
\end{array}\right.
$$

In (2), $V_{O A B C}$ are the target output voltages. $L$ and $C$ are respectively the inductance and capacitance of the output filter. $R$ is the resistance of the load. $i_{L A, B, C}$ are the current in the filter inductors. Assume three modulating signals $m_{A}, m_{B}$, and $m_{C}$; in the particular case when the dc voltages are quite equal to each other, the terms including the switching functions in (2) can be expressed in an average sense as:

$$
\left\{\begin{array}{l}
\frac{1}{L} \sum_{i=1}^{n} S_{A i} V_{d c, A i}=\frac{1}{L} m_{A} V_{d c} \\
\frac{1}{L} \sum_{i=1}^{n} S_{B i} V_{d c, B i}=\frac{1}{L} m_{B} V_{d c} \\
\frac{1}{L} \sum_{i=1}^{n} S_{C i} V_{d c, C i}=\frac{1}{L} m_{C} V_{d c}
\end{array}\right.
$$$$
\text { where } V_{d c}=n V_{d c, i \quad(\mathrm{i}=1, \ldots, \mathrm{n})}
$$

Using the inverse park transformation $\left(P(\theta)^{-1}\right)$ given in (5), equations (2) and (3) can be reported in a rotating reference frame synchronized with target output voltages frequency which yields:

$$
\left\{\begin{array}{l}
\frac{d}{d t} V_{o d}=-\frac{1}{R C} V_{o d}+\omega V_{o q}+\frac{1}{C} i_{L d} \\
\frac{d}{d t} V_{o q}=-\frac{1}{R C} V_{o q}-\omega V_{o d}+\frac{1}{C} i_{L q} \\
\frac{d}{d t} i_{L d}=-\frac{r}{L} i_{L d}+\omega i_{L q}-\frac{1}{L} V_{o d}+\frac{1}{L} m_{d} V_{d c} \\
\frac{d}{d t} i_{L q}=-\frac{r}{L} i_{L q}-\omega i_{L d}-\frac{1}{L} V_{o q}+\frac{1}{L} m_{q} V_{d c}
\end{array}\right.
$$




$$
\begin{aligned}
& \text { where: }\left\{\begin{array}{l}
V_{d c}=n V_{d c, i}(\mathrm{i}=1, \ldots, \mathrm{n}) \\
\frac{d}{d t} V_{d c, i}=\frac{1}{c_{i}} i_{c i}
\end{array}\right. \\
& {\left[\begin{array}{l}
x_{d} \\
x_{q} \\
x_{o}
\end{array}\right]=\underbrace{\sqrt{\frac{2}{3}}\left[\begin{array}{ccc}
\cos \theta & \sin \theta & 0 \\
-\sin \theta & \cos \theta & 0 \\
0 & 0 & 1
\end{array}\right]\left[\begin{array}{rrr}
1 & -\frac{1}{2} & -\frac{1}{2} \\
0 & \frac{\sqrt{3}}{2} & -\frac{\sqrt{3}}{2}
\end{array}\right]}_{P(\theta)^{-1}}\left[\begin{array}{l}
x_{A} \\
x_{B} \\
x_{C}
\end{array}\right]}
\end{aligned}
$$

\section{B. Converter's modeling with unknown loads}

Let $i_{O A, B, C}$ denote the currents through all output loads. The dynamics of the output voltages, in a stationary three phase frame, can be expressed as:

$$
\left\{\begin{array}{l}
\frac{d}{d t} V_{O A}=\frac{1}{C} i_{L A}-\frac{1}{C} i_{O A} \\
\frac{d}{d t} V_{O B}=\frac{1}{C} i_{L B}-\frac{1}{C} i_{O B} \\
\frac{d}{d t} V_{O C}=\frac{1}{C} i_{L C}-\frac{1}{C} i_{O C}
\end{array}\right.
$$

The dynamics of the currents in inductors expressed in (2) remains unchanged. In the same manner, using the inverse park transformation $\left(P(\theta)^{-1}\right)$, the converter's model can be expressed in a rotating reference frame synchronized with target output voltages frequency as follows:

$$
\begin{aligned}
& \left\{\begin{array}{l}
\frac{d}{d t} V_{o d}=\omega V_{o q}-\frac{1}{C} i_{o d}+\frac{1}{C} i_{L d} \\
\frac{d}{d t} V_{o q}=-\omega V_{o d}-\frac{1}{C} i_{o q}+\frac{1}{C} i_{L q} \\
\frac{d}{d t} i_{L d}=-\frac{r}{L} i_{L d}+\omega i_{L q}-\frac{1}{L} V_{o d}+\frac{1}{L} m_{d} V_{d c} \\
\frac{d}{d t} i_{L q}=-\frac{r}{L} i_{L q}-\omega i_{L d}-\frac{1}{L} V_{o q}+\frac{1}{L} m_{q} V_{d c}
\end{array}\right. \\
& \text { where: }\left\{\begin{array}{l}
V_{d c}=n V_{d c, i}(\mathrm{i}=1, \ldots, \mathrm{n}) \\
\frac{d}{d t} V_{d c, i}=\frac{1}{c_{i}} i_{c i}
\end{array}\right.
\end{aligned}
$$

\section{CONVERTER'S CONTROLLER DESIGN}

\section{A. Converter's control with resistive load}

The input-output feedback linearization method can be established through three steps. The first one consists in differentiating the output variables $\left(V_{o d}\right.$ and $\left.V_{o q}\right)$ many times until at least one of the inputs $m_{d}$ and $m_{q}$ appears.
Differentiating one time equation (4), a modified state-space model expressed in a controllable canonical form is derived as follows:

$$
\begin{aligned}
& \int \frac{d}{d t} V_{o d}=-\frac{1}{R C} V_{o d}+\omega V_{o q}+\frac{1}{C} i_{L d} \\
& \frac{d^{2}}{d t^{2}} V_{o d}=\left[\frac{1}{(R C)^{2}}-\omega^{2}-\frac{1}{L C}\right] V_{o d}-\frac{2 \omega}{R C} V_{o q} \\
& +\left[-\frac{1}{R C^{2}}-\frac{r}{L C}\right] i_{L d}+\frac{2 \omega}{C} i_{L q}+\frac{m_{d} V_{d c}}{L C} \\
& \frac{d}{d t} V_{o q}=-\frac{1}{R C} V_{o q}-\omega V_{o d}+\frac{1}{C} i_{L q} \\
& \frac{d^{2}}{d t^{2}} V_{o q}=\frac{2 \omega}{R C} V_{o d}+\left[\frac{1}{(R C)^{2}}-\omega^{2}-\frac{1}{L C}\right] V_{o q}-\frac{2 \omega}{C} i_{L d} \\
& +\left[-\frac{1}{R C^{2}}-\frac{r}{L C}\right] i_{L q}+\frac{m_{q} V_{d c}}{L C} \\
& \text { where: }\left\{\begin{array}{l}
V_{d c}=n V_{d c, i(\mathrm{i}=1, \ldots, \mathrm{n})} \\
\frac{d}{d t} V_{d c, i}=\frac{1}{c_{i}} i_{c i}
\end{array}\right.
\end{aligned}
$$

With reference to (8), a linear relationship may be established between $V_{o d}, V_{o q}$ and the new control input $F_{d}$ and $F_{q}$ such that:

$$
\left\{\begin{array}{l}
\frac{d^{2}}{d t^{2}} V_{o d}=F_{d} \\
\frac{d^{2}}{d t^{2}} V_{o q}=F_{q}
\end{array}\right.
$$

By equating (9) to (8), and assuming the dc voltages are perfectly regulated and have the same value, the control laws $m_{d}$ and $m_{q}$ are derived as shown in (10) where $\omega_{o}=\frac{1}{\sqrt{L C}}$ is the corner frequency of the filter.

$$
\left\{\begin{array}{c}
m_{d}=\frac{1}{\omega_{0}^{2} V_{d c}}\left[\begin{array}{c}
F_{d}-\left[\frac{1}{(R C)^{2}}-\omega^{2}-\omega_{0}^{2}\right] V_{o d}+\frac{2 \omega}{R C} V_{o q} \\
+\left[\frac{1}{R C^{2}} \frac{r}{L C}\right] i_{L d}-\frac{2 \omega}{C} i_{L q}
\end{array}\right] \\
\frac{d^{2}}{d t^{2}} V_{o q}=\frac{2 \omega}{R C} V_{o d}+\left[\frac{1}{(R C)^{2}}-\omega^{2}-\omega_{0}^{2}\right] V_{o q}-\frac{2 \omega}{C} i_{L d} \\
+\left[-\frac{1}{R C^{2}}-\frac{r}{L C}\right] i_{L q}+\frac{m_{q} V_{d c}}{L C}
\end{array}\right.
$$


The final step consists in determining the linear control laws $F_{d}$ and $F_{q}$ so that the error between the output voltages and their target references exhibits a linear second order dynamics:

$$
\left\{\begin{array}{l}
\frac{d^{2}}{d t^{2}} e_{d}+k_{11} \frac{d}{d t} e_{d}+k_{12} e_{d}+k_{12} k_{1 I} \int e_{d} d t=0 \\
\frac{d^{2}}{d t^{2}} e_{q}+k_{21} \frac{d}{d t} e_{q}+k_{22} e_{q}+k_{22} k_{1 I} \int e_{q} d t=0
\end{array}\right.
$$

In (11), $\mathrm{e}_{\mathrm{d}}$ and $\mathrm{e}_{\mathrm{q}}$ are defined as: $e_{d}=V_{o d}{ }^{*}-V_{o d}$ and $e_{q}=V_{o q} *-V_{o q} \cdot V_{o d} *$ and $V_{o q} *$ denote the desired reference signals. The parameters $k_{i j}$ are determined using pole placement method. Using the relationship defined in (9) the linear control laws are subsequently derived as follows:

$$
\left\{\begin{aligned}
F_{d}= & \frac{d^{2}}{d t^{2}} V_{o d}^{*}+k_{11} \frac{d}{d t} V_{o d}^{*}+k_{12} V_{o d}^{*}+\left[\frac{k_{11}}{R C}-k_{12}\right] V_{o d} \\
& -k_{11} \omega V_{o q}-\frac{k_{11}}{C} i_{L d}+k_{12} k_{11} \int\left(V_{o d}^{*}-V_{o d}\right) d t \\
F_{q}= & \frac{d^{2}}{d t^{2}} V_{o q}^{*}+k_{21} \frac{d}{d t} V_{o q}^{*}+k_{22} V_{o q}^{*}+k_{21} \omega V_{o d} \\
& +\left[\frac{k_{21}}{R C}-k_{22}\right] V_{o q}-\frac{k_{21}}{C} i_{L q}+k_{22} k_{2 I} \int\left(V_{o q}^{*}-V_{o q}\right) d t
\end{aligned}\right.
$$

The control laws are implemented as follows; the terms $F_{d}$ and $F_{q}$ determined in (12) are used in (10). Next, by using the direct Park transformation, the three modulating signals $m_{A}$, $m_{B}$, and $m_{C}$ are deduced from the control laws $m_{d}$ and $m_{\mathrm{q}}$ calculated in (10). Finally, the switching pattern of the converter is derived by using the multi carrier based modulation strategy.

\section{B. Converter's control with unknown load}

Using the same philosophy, the control laws $m_{d}$ and $m_{q}$ as well as the nonlinear terms $F_{d}$ and $F_{q}$ are derived as follows;

$$
\begin{aligned}
& m_{d}=\frac{1}{\omega_{0}^{2} V_{d c}}\left[\begin{array}{c}
F_{d}+\left[\omega^{2}+\omega_{0}^{2}\right] V_{o d}+\frac{1}{C} \chi_{L d}+\frac{\omega}{C} i_{o q} \\
+r \omega_{0}^{2} i_{L d}-\frac{2 \omega}{C} i_{L q}
\end{array}\right] \\
& m_{q}=\frac{1}{\omega_{0}^{2} V_{d c}}\left[\begin{array}{c}
F_{q}+\left[\omega^{2}+\omega_{0}^{2}\right] V_{o q}+\frac{1}{C} \chi_{L q}-\frac{\omega}{C} i_{o d} \\
+r \omega_{0}^{2} i_{L q}+\frac{2 \omega}{C} i_{L q}
\end{array}\right] \\
& \text { where } \chi_{L d}=\frac{d}{d t} i_{L d} \text { and } \chi_{L q}=\frac{d}{d t} i_{L q}
\end{aligned}
$$

$$
\left\{\begin{aligned}
F_{d} & =\frac{d^{2}}{d t^{2}} V_{o d}^{*}+k_{11} \frac{d}{d t} V_{o d}^{*}+k_{12} V_{o d}^{*}-k_{12} V_{O d} \\
& -k_{11} \omega V_{O q}-\frac{k_{11}}{C} i_{L d}+\frac{k_{11}}{C} i_{o d}+k_{12} k_{1 I} \int\left(V_{o d}^{*}-V_{o d}\right) d t \\
F_{q} & =\frac{d^{2}}{d t^{2}} V_{o q}^{*}+k_{21} \frac{d}{d t} V_{o q}^{*}+k_{22} V_{o q}^{*}+k_{21} \omega V_{O d} \\
& -k_{22} V_{O q}-\frac{k_{21}}{C} i_{L q}-\frac{k_{21}}{C} i_{O q}+k_{22} k_{2 I} \int\left(V_{o q}^{*}-V_{o q}\right) d t
\end{aligned}\right.
$$

\section{NUMERICAL SIMULATIONS}

A numerical model of a cascaded H-bridge seven-level inverter feeding a three-phase load through a second order lowpass filter is constructed using software program. The electrical parameters of the system under study as well as the controller parameters are reported in table I below.

TABLE I

PARAMETERS OF THE SYSTEM AND CONTROLLER

\begin{tabular}{|c|c|}
\hline DC supply of H-bridge & $V_{D C}=50 \mathrm{~V}$ \\
\hline Switching frequency & $f_{s w}=5 \mathrm{kHz}$ \\
\hline Load parameters & $R=30 \Omega$ \\
\hline \multirow{2}{*}{ Filter parameters } & $r=0.15 \Omega$ \\
\cline { 2 - 2 } & $L=2 \mathrm{mH}$ \\
\cline { 2 - 2 } & $c=12 \mu \mathrm{F}$ \\
\hline \multirow{2}{*}{ Controller parameters } & $k 2=25.1667 * 10^{6}$ \\
\cline { 2 - 2 } & $k 1=2.3888^{*} 10^{2}$ \\
\cline { 2 - 2 } & $k i=0.227^{3} 10^{3}$ \\
\hline
\end{tabular}

Every 7-L CHB arm is formed by series connection of three independent single phase inverters. The modulation technique, used to generate the gate control signals of the different power switches, is sinusoidal Pulse Width Modulation. Several carrier waves having the same frequency, six in this case, are compared to a modulating one. If the sinusoidal signal is greater than the triangular carrier, the device to which is allocated is turned on. Fig. 2a shows that the sampled phase voltage $\mathrm{U}_{\mathrm{A}}$ is synthesized by seven levels: $3 \mathrm{~V}_{\mathbf{d c}}, 2 \mathrm{~V}_{\mathbf{d c}}, \mathrm{V}_{\mathbf{d c}}$, $0,-V_{\mathbf{d c}},-2 \mathrm{~V}_{\mathbf{d c}},-3 \mathrm{~V}_{\mathbf{d c}}$. Its harmonic spectrum presents a low harmonic distortion rate, Fig. 2b; this asserts the interest of multi level inverter.

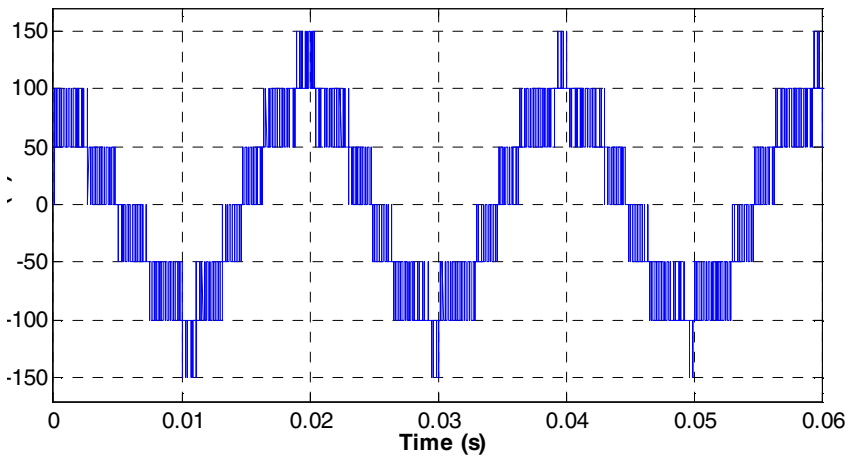

Figure 2a. $\mathrm{U}_{\mathrm{A}}$ waveform. 


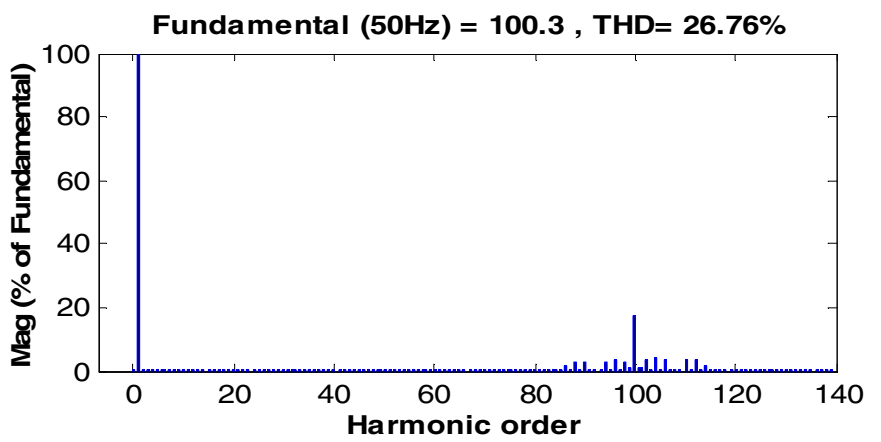

Figure $2 b$. Harmonic spectrum of $U_{A}$.

\section{A. Converter's simulation with known resistive load}

The first part of this section is devoted to the simulation of converter's feedback linearization control when feeding a resistive load. The efficiency of established control laws, given by equation (12), will be tested. The load impedance has a value of $25 \Omega$.

The references voltages of $\left(\mathrm{V}_{\mathrm{OA}}, \mathrm{V}_{\mathrm{OB}}, \mathrm{V}_{\mathrm{OC}}\right)$ are held at a maximum of $\mathrm{V}_{\text {omax }}=100 \mathrm{~V}$ and a frequency equal to $50 \mathrm{~Hz}$. Their d-q components are $\mathrm{V}^{*}{ }_{\text {od }}$ and $\mathrm{V}^{*}{ }_{\mathrm{oq}}$. These should be expressed as follows:

$$
\left\{\begin{array}{l}
V_{o d}^{*}=V_{o \text { max }} * \sqrt{\frac{3}{2}}=122,47 \mathrm{~V} \\
V_{o q}^{*}=0 \mathrm{~V}
\end{array}\right.
$$

Fig. 3a and Fig. 3b show the waveforms of control laws $U_{d}$ and $U_{q}$ which are calculated at each sampling time by the proposed controller. Fig. 4 depicts the waveforms of the instantaneous three output voltages $\mathrm{V}_{\mathrm{OA}}, \mathrm{V}_{\mathrm{OB}}$, and $\mathrm{V}_{\mathrm{OC}}$. As can be seen, their peak magnitude and frequency are very close to their references.

This can also be emphasized by inspecting Fig.5 which clearly show that the q component of the output voltage is quite zero whereas the $\mathrm{d}$ component is close to $122 \mathrm{~V}$. The settling time after the start up of the converter is about a period i.e. $20 \mathrm{~ms}$. Furthermore, It can be noticed that the set of output filter voltages track their references without any overshoot.

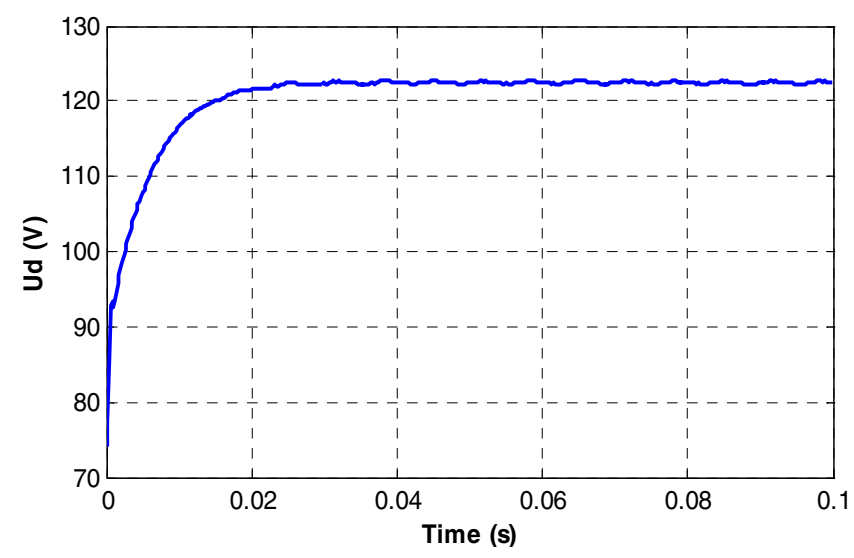

Figure 3a. Control voltages Ud.

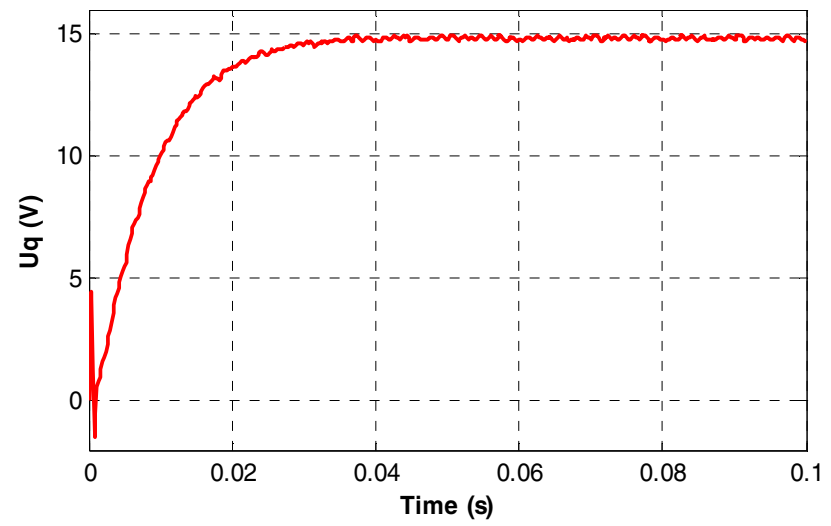

Figure 3b. Control voltage Uq.

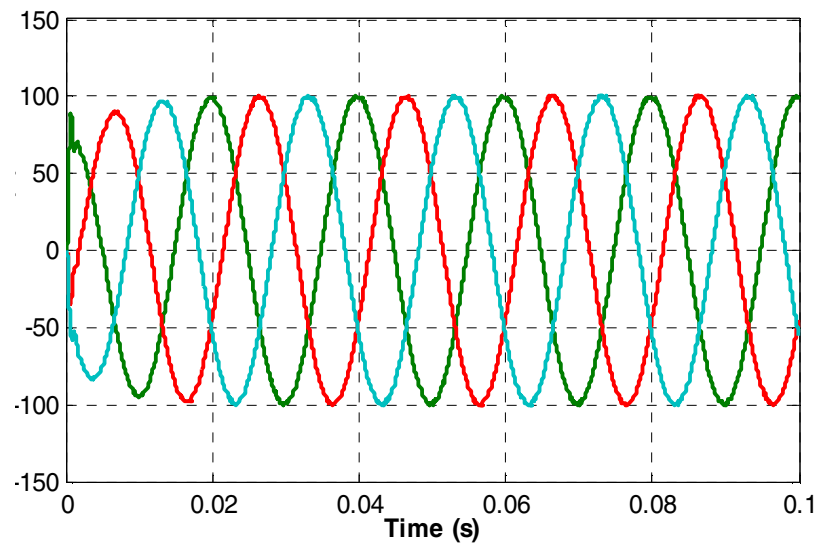

Figure 4. Responses of output filter voltages $\mathrm{V}_{\mathrm{OA}}, \mathrm{V}_{\mathrm{OB}}$ and $\mathrm{V}_{\mathrm{OC}}$.

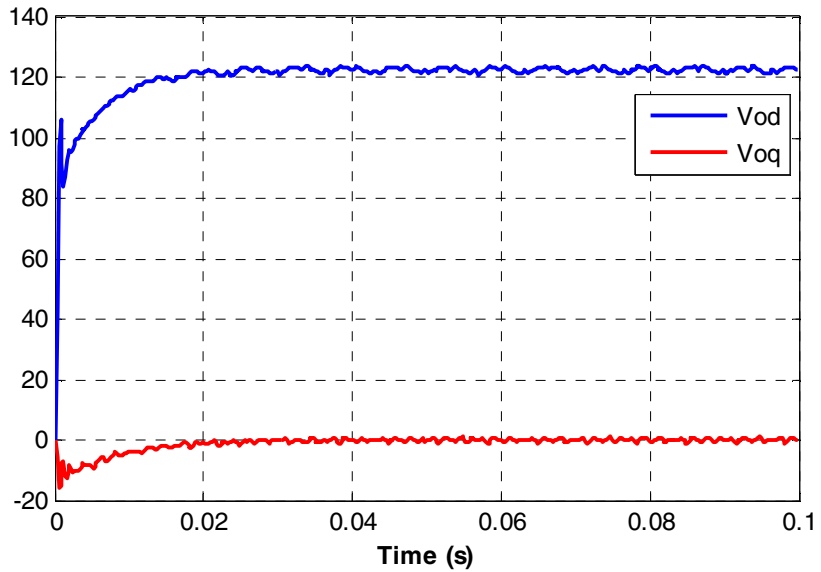

Figure 5. Vod and Voq .

The current load, regulated similarly to the voltage, is almost sinusoidal as illustrated in Fig. 6. 


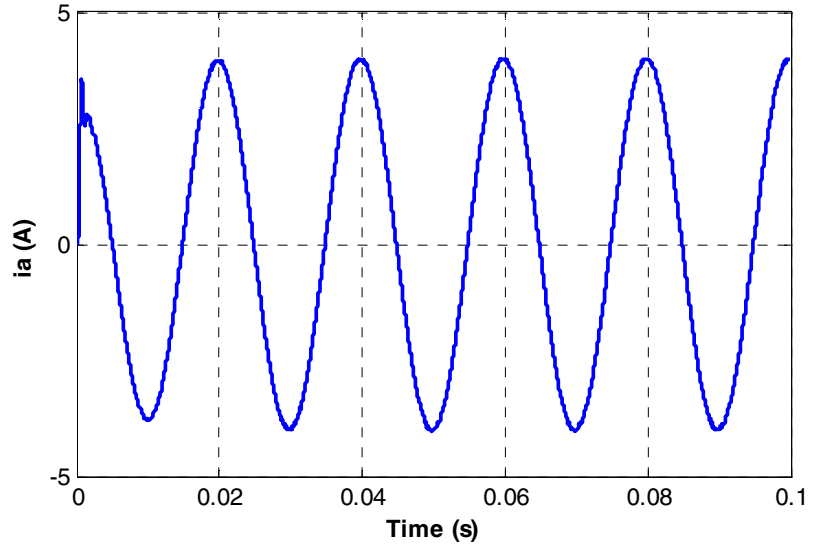

Figure 6. Load current $i_{a}$.

The behavior of the variables previously mentioned confirms the validity of the model described in section II.A and the performance of the proposed control method. It also proves the controller ability to impose specified inverter dynamics.

\section{B. Converter's simulation with arbitrary load}

The purpose of this part is to validate a generalized H-bridge model without the need of load parameters.

The considered load is constituted by two different charges connected in parallel: R and RL.

The voltage references are set to 100V. Fig. 7a and Fig. 7b exhibit the evolution of the system linear control laws. Meanwhile, Fig. 8 shows the dynamic responses of the output voltages variables. One can observe that the system is perfectly regulated and presents a faster time response approximately $10 \mathrm{~ms}$. During the transient, few oscillations appear and do not acquire high amplitudes.

The Fourier analysis of one phase output voltage gives a very low harmonic distortion rate $0.64 \%$ as depicted in Fig. 8 b. The generated voltages used to supply the load are nearly sinusoidal. Thus, the selected LC filter is efficient.

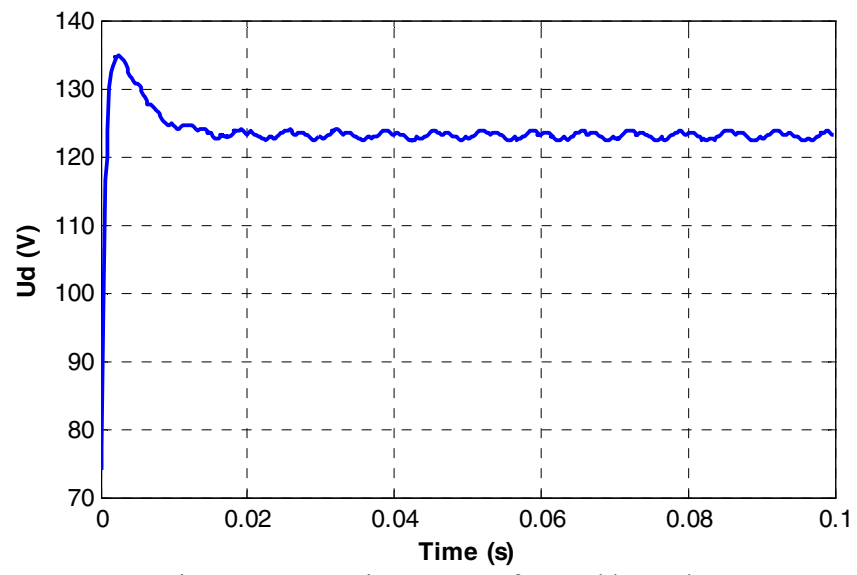

Figure 7a. Dynamic response of control law Ud.

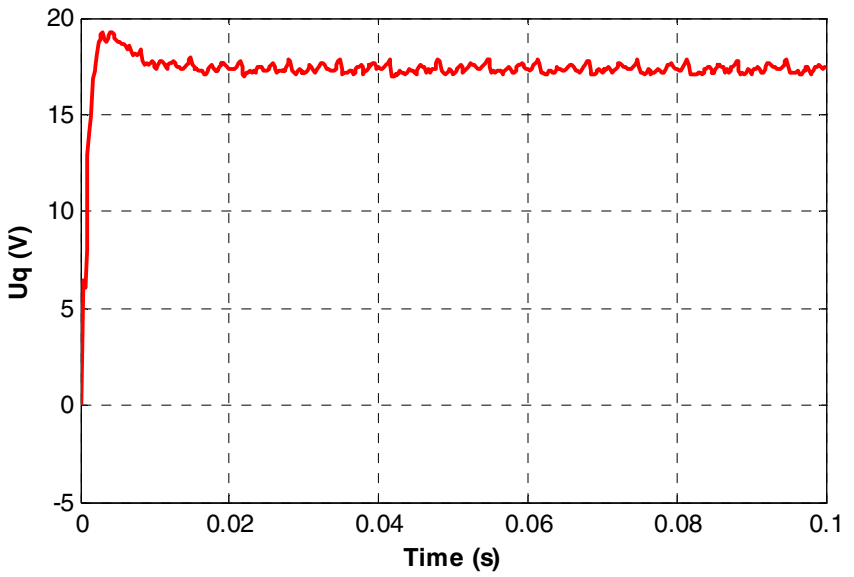

Figure $7 \mathrm{~b}$. Dynamic response of control law Uq.
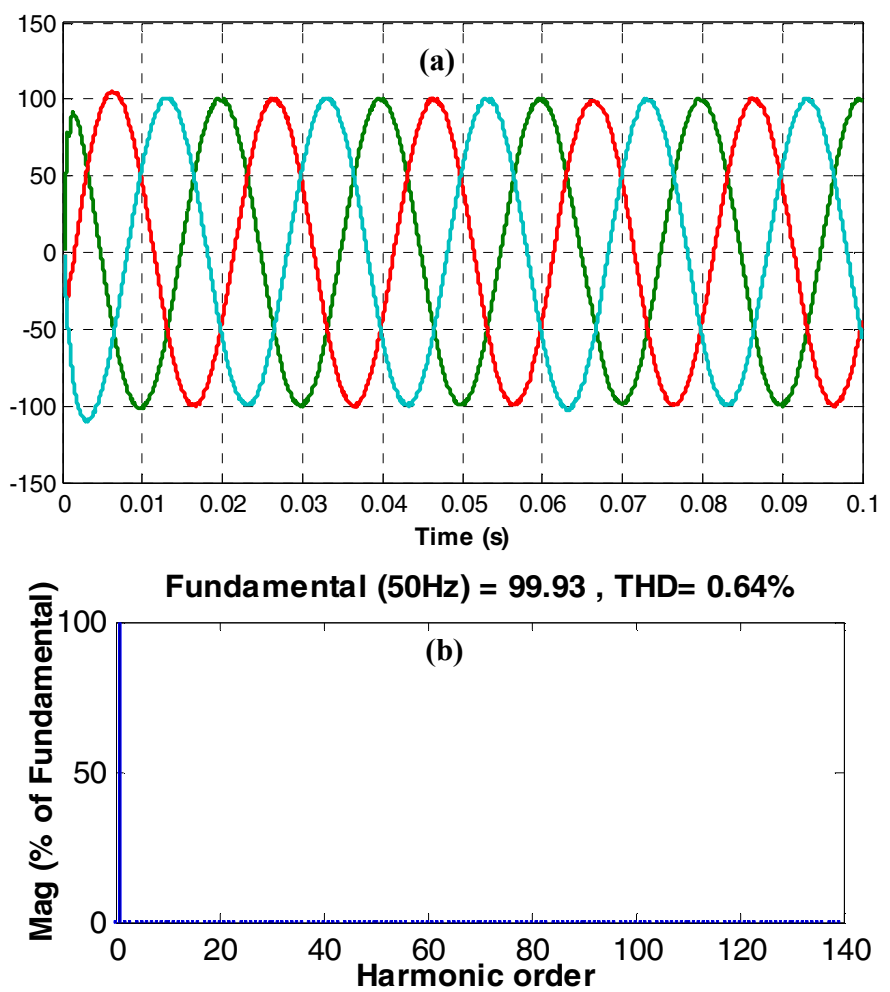

Figure 8. (a): Output voltages waveforms, (b):THD of $\mathrm{V}_{\mathrm{OA}}$.

In the last simulations, the influence of the load variation on the control strategy will be investigated. The RL load is disconnected at time $t=0.06 \mathrm{~s}$. Fig. 9 below shows the abrupt decrease of the load current owing to this phenomena. Figs. 10 and 11 show that the output voltages remain stable and constant. Subsequently they are not affected by the load disturbance. 


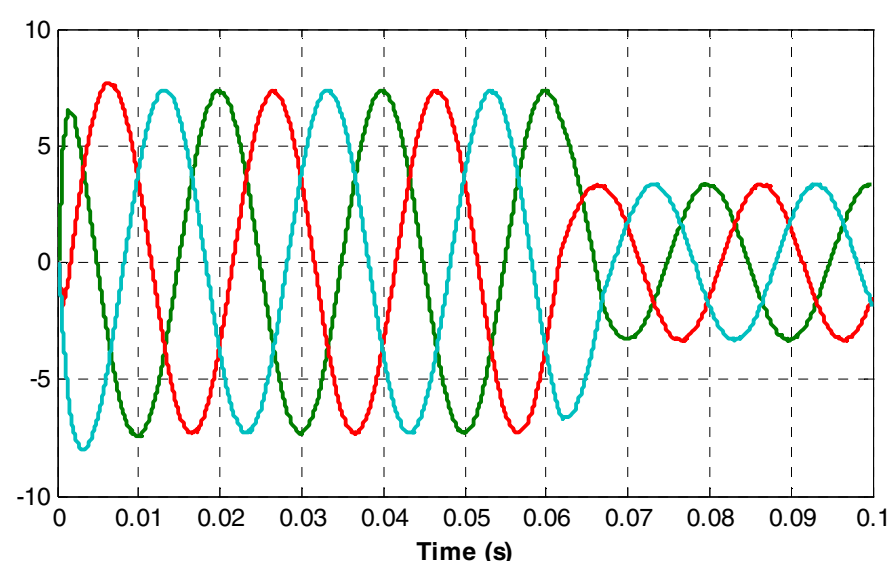

Figure 9. Load currents waveforms.

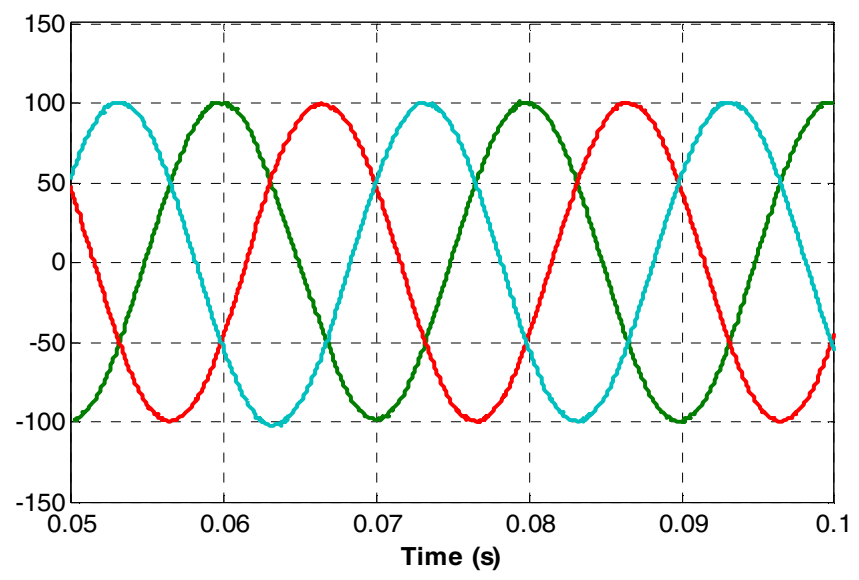

Figure.10. Evolution of $\mathrm{V}_{\mathrm{OA}}, \mathrm{V}_{\mathrm{OB}}$ and $\mathrm{V}_{\mathrm{OC}}$.

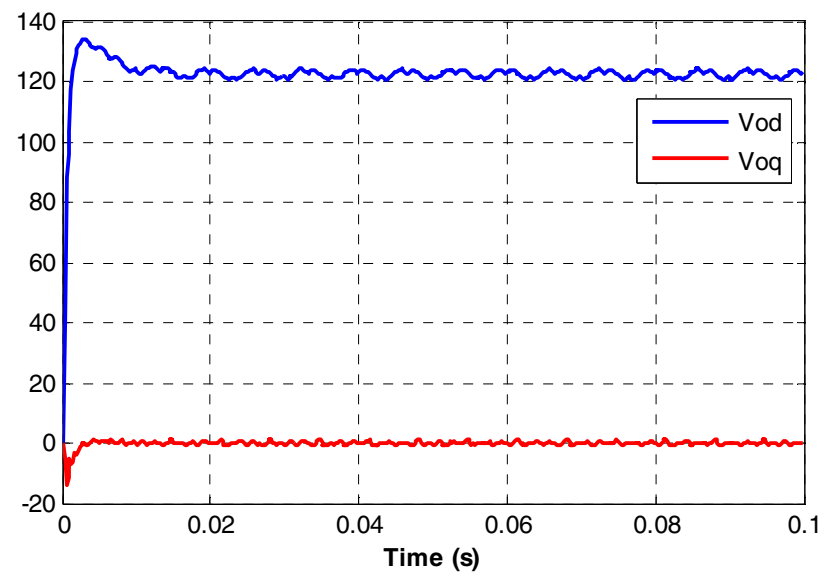

Figure.11. Vod and Voq versus time.

Hence, it can be concluded that the system conserves his stability which confirms that the control algorithm studied in this work is robust and reliable.

\section{CONCLUSION}

In this paper, tow different converter's models have been developed. The established H-Bridge models have the advantage to be easily extendable to any number of voltage levels. A feedback linearizing controller was constructed with the aim to drive the output voltage amplitude and frequency to their references. The simulation results corroborate the high regulation ability of the established algorithm. The feedback linearization asserted his excellent effectiveness even in case of load disconnection.

APPENDIX

Nomenclature

$U_{A}, U_{B}$, and $U_{C}$ : output voltages of the H-bridge inverter $V_{O A B C}$ : load voltages

$V_{o d}, V_{o q}$ : voltages representation of $V_{O A B C}$ in Park frame

$V_{d c, x i}: i^{\text {th }} \mathrm{dc}$ voltage of the $\mathrm{x}^{\text {th }}$ phase

$r, L$ : resistance and inductance of the filter inductors

$C$ : Capacitance of the filter capacitors

$i_{L A, B, C}$ : current in the filter inductors

$i_{L d}, i_{L q}$ : currents representation of $i_{L A, B, C}$ in Park frame

$R:$ resistance of the load

$m_{A}, m_{B}$, and $m_{C}$ : modulation index

$\omega$ : angular frequency of $V_{O A B C}$

\section{REFERENCES}

[1] M. Malinowski, K. Gopakumar, J. Reodriguez and M. A. Pérez, "A survey on cascaded multilevel inverters," IEEE Transactions on Idustrial Electronics, vol. 57, pp. 2197 - 2206, July 2010.

[2] M. Asoodar, and H. Iman-Eini,“ A New Switching Algorithm in Back to Back CHB Multilevel Converters with the Advantage of Eliminating Isolation Stage,"11th Environment and Electrical Engineering International Conference, pp731 - 736, Venice, 2012.

[3] L. Yacoubi, K. Al Haddad, L. A. Dessaint anf F. Fnaiech,“ A DSP-Based Implementation of a Nonlinear Model Refrence Adaptive Control for a Three-Phase NPC Boost Rectifer Prototype," IEEE Transactions on Power Electronics, vol. 20, pp. 1084-1092, Sept. 2005.

[4] C.D. Townsend, T.J. Summers, and R.E. Betz," Control and Modulation Scheme for a Cascaded H-Bridge Multi-Level Converter in Large Scale Photovoltaic Systems," IEEE Energy Conversion Congress and Exposition, Raleigh, USA, pp 3707-3714, 2012

[5] S. Cobreces, J. Bordonau, J. Salaet, E. J. Bueno and Francisco, and J. Rodriguez," Exact Linearization Nonlinear Neutral-Point Voltage Control for Single-Phase Three-Level NPC Converters," IEEE Tansactions on Power Electronics, no. 10, vol. 24, October 2009.

[6] N. Farokhnia, S.H. Fathi, and H. Toodeji," Direct Nonlinear Control for Individual DC Voltage Balancing in Cascaded Multilevel DSTATCOM," International Conference on Electric Power and Energy Conversion Systems, sharjah, 2009.

[7] H. Zheng, and D. Shuai "“ Nonlinear control of Boost converter by state feedback exact linearization," 24th Chinese Control and Decision Conference, pp3502 - 3506, Taiyuan, 2012.

[8] M. Hamouda, K. AL-Haddad, F. Fnaiech, and H. Blanchette, "InputState Feedback Linearization Control of Two-Stage Matrix Converters Interfaced With High-Speed Microturbine Generators", IEEE EPC 2007 conference, pp. 302-307, Montreal, QC, Canada, 25-26 October 2007.

[9] M.Hamouda, A. Marzouki and F. Fnaiech, "Sensorless Nonlinear Control for a Three-Phase PWM AC-DC Converter », in Proc.IEEE ISIE 2010 conference, pp. 1052-1057. 